\title{
Prevalence of anxiety among environmental and occupational health students in Qazvin University of Medical Sciences, Iran, in 2015
}

\author{
Jamali HA, $\mathrm{PhD}^{1}$, Ghalenoei M, PhD Student ${ }^{2}$, Yazdani Aval M, PhD Student ${ }^{3}$, Taban E, \\ PhD Student ${ }^{2}$, Kolahdouzi M, MSc ${ }^{4}$, Jalilian J, MSc ${ }^{5}$, Rostami Aghdam Shendi M, MSc ${ }^{6 *}$ \\ 1- Assistant Prof, Dept. of Environmental Health, Faculty of Health, Qazvin University of Medical Sciences, Qazvin, Iran. \\ 2-PhD Student, Dept. of Occupational Health Engineering, Faculty of Medical Sciences, Tarbiat Modares University, \\ Tehran, Iran. 3-PhD Student, Dept. of Occupational Health Engineering, Faculty of Health, Hamadan University of Medical \\ Sciences, Hamadan, Iran. 4-MSc in Occupational Health, Dept. of Occupational Health Engineering, School of Public \\ Health, Shahid Sadoughi University of Medical Sciences, Yazd, Iran. 5-MSc in Occupational Health, Dept. of Toxicology \\ and Pharmacology, Faculty of Pharmacy, Mazandaran University of Medical Sciences, Sari, Iran. 6-MSc in Occupational \\ Health, Dept. of Occupational Health Engineering, Faculty of Medical Sciences, Tehran University, Tehran, Iran.
}

\begin{abstract}
Received: February 2017, Accepted: August 2017

Background: Anxiety disorders are among the most common types of psychological disorders in the world. Anxiety is an inseparable part of every person's life and it seems that it is experienced more severely by university students. The present study aimed to investigate the prevalence of anxiety and its related factors among environmental and occupational health students.

Materials and Methods: In this descriptive cross-sectional study in 2015, the participants were selected through census-based sampling; all the Bachelor students (continuous and discontinuous) of environmental and occupational health (141 respondents) from Qazvin University of Medical Sciences, Iran, participated in this research. Data were collected using a demographic questionnaire and Spielberger State-Trait Anxiety Inventory measuring respondents' level of anxiety. The collected data were analyzed by independent samples t-test, analysis of variance, and Pearson correlation in SPSS software.

Results: The prevalence rates of state and trait anxiety in the sample were $29.1 \%$ and $20.6 \%$, respectively. Furthermore, $29.1 \%$ of students of environmental health and $57.9 \%$ of students of occupational health suffered from moderate to high levels of anxiety. The greatest prevalence of trait anxiety among students of environmental and occupational health was recorded for below moderate anxiety with indices of $72.8 \%$ and $84.2 \%$, respectively. On the other hand, no significant relationship was observed between students' year of study (ranging from the first to the fourth year) and state/trait anxiety. However, the results of Pearson correlation showed that there was a significant negative relationship between students' grade point average and trait anxiety.

Conclusions: Anxiety among university students of environmental and occupational health range from moderate to high. Some measures should be taken to reduce this level of anxiety.
\end{abstract}

Keywords: Anxiety, Environmental Health, Occupational Health,

\section{Introduction}

As an old subject, anxiety has been experienced by humans during history and in different cultural backgrounds. Anxiety is defined as a vague and unpleasant feeling origin of which is unknown to individuals (1). It is a natural reaction to stress and affects both body and mind. Anxiety plays an important role in people's lives (2). In the current century, industrialization has exercised its consequences in various socio-cultural, religious, and psychological ${ }^{*}$ aspects of

* Corresponding author: Maryam Rostami Aghdam Shendi, Dept. of Occupational Health Engineering, Faculty of Medical Sciences, Tehran University, Tehran, Iran.

E-mail: m_rostami_68@yahoo.com 
humans' lives. People are therefore more vulnerable to psychological disorders, especially anxiety (3). Anxiety disorder is the third common psychological disorder in the world following major depressive disorder and alcohol dependence disorder. Epidemiological studies have reported a prevalence rate of $13.3 \%$ for social anxiety disorder during a typical person's life (3). Anxiety is an integral part of all people's lives; nevertheless, it seems that university students experience more serious forms of anxiety (4). Anxiety occurs alone or along with other psychological disorders. University students are under the pressure of various stressors including university tuitions, challenges in adaptation to the educational system, vague future, pressure of different courses, new lifestyle, disturbance of the sleeping and waking hours, dormitory life, lack of enough time and facilities for recreation, parents' high expectations, and university exams and assignments $(5,6)$. A research project focusing on university students of Tarbiat Modares University, Tehran, Iran, who lived in dormitories showed that $39.5 \%$ of the participants suffered from anxiety (7). Severe and long-lasting anxiety leads to psychosomatic diseases such as blood pressure, coronary heart diseases and angina (8). It may also cause psychological disorders like depression (9). It is believed that high level of anxiety negatively influences university students' health (5). As a result, considerable attention has been paid to this subject in recent years, with the ultimate goal of designing appropriate interventions to minimize or eliminate anxiety. In addition, high quality education is an integral component for preparing students in the fields of environmental and occupational health. Upon being trained as experts in these two fields, students can be recruited by various organizations to address environmental and occupational health problems (10). State anxiety is situational and stems from stressful conditions (e.g. arguments, loss of social opportunities, security threats, and loss of health) and may appear in a particular period of a person's life (11). In contrast, trait anxiety has to do with individual differences in responding to threatening situations with various levels of state anxiety (12).

Anxiety can be considered as one of the main neuropsychiatric disorders and one of the main reasons for depression. If anxiety lasts for a long time, it leads to depression. Anxiety is an unpleasant feeling of stress that stems from an unknown origin. Some psychologists believe that all psychological diseases are the result of anxiety (13).

The two majors of environmental and occupational health in Qazvin University of Medical Sciences, Qazvin, Iran, have received less attention in comparison with other healthrelated fields (such as medicine, nursing, pharmacy, dentistry. The aim of this study was to investigate the prevalence of anxiety and its related factors among environmental and occupational health students in Qazvin University of Medical Sciences, in 2015.

\section{Materials and Methods}

In this descriptive cross-sectional study, the participants were selected through censusbased sampling; all the university students of environmental and occupational health (141 respondents) at the Bachelor program (continuous and discontinuous) of Qazvin University of Medical Sciences participated in this research. The survey used for data collection comprised two sections; a demographic questionnaire which was developed to collect participants' background information and Spielberger State-Trait Anxiety Inventory to measure respondents' level of anxiety. This inventory is a highly valid instrument and a standard test for anxiety (14). This questionnaire was developed and used by Spielberger in 1983. In 2005, it was normalized for Iranian population and its validity was assessed and confirmed through concurrent criterion validity. Some other prominent researchers have also evaluated the reliability of this questionnaire. The reliability of this instrument (calculated by Cronbach's 
alpha) is above 0.9 for state and trait anxiety $(15,16)$. It should be noted that this questionnaire comprises to dimensions: state and trait anxiety. Spielberger has defined state anxiety as an unpleasant emotional arousal which does not last for a long time. Trait anxiety, on the other hand, reflects the existence of stable individual differences in the tendency of responding with anxiety to threatening situations. More specifically, according to trait anxiety, people tend to respond differently to threatening situations. The Spielberger State-Trait Anxiety Inventory involves two sets of questions (40 questions in total), with the first 20 questions measuring state anxiety and the second 20 questions evaluating individuals' trait anxiety. Participants should respond to each item on a four-point likert scale with anchors at never, sometimes, almost always, and always. Depending on the total score, respondents may be classified into one of these six categories: mild anxiety (20-31), below moderate anxiety (32-42), above moderate anxiety (43-53), rather high anxiety (54-64), and high anxiety (65-75) (12). The demographic questionnaire collected data on participants' educational level, gender, major, grade point average (GPA), etc. After finalizing the number of students who would participate in the study, a training session was held for them clearly explaining the procedure for answering state and trait anxiety questions. The students were instructed that while answering state anxiety questions, they should consider their feelings at the moment. They were also told that in order to answer trait anxiety questions, they should take their dominant feelings (e.g. the feelings that they usually have in their daily lives) into account. In order to encourage respondents to provide honest answers, they were assured that their answers would remain strictly confidential and the results of analyzing their responses would be shared with them. The questionnaires were subsequently distributed among the participants and completed by them on the spot. There was no pressure on participants while completing the survey, so they could allocate as much time as they wanted in order to answer the questions. The collected data were fed into SPSS software (version 20.0, IBM Corporation, Armonk, NY, USA), followed by conducting Pearson product moment correlation, one-way analysis of variance (ANOVA), and independent samples $\mathrm{t}$-test. The significance level was set at $\mathrm{P}<$ 0.05. Kolmogorov-Smirnov test was done for evaluation of data distribution.

\section{Results}

This study was conducted among 141 female and male university students of environmental and occupational health.

Table 1: Participants' demographic information $(n=141)$

\begin{tabular}{|c|c|c|c|c|}
\hline \multicolumn{3}{|c|}{ Variable } & Number & Percentage (\%) \\
\hline \multirow{2}{*}{ Gender } & \multicolumn{2}{|c|}{ Female } & 108 & 76.6 \\
\hline & \multicolumn{2}{|c|}{ Male } & 33 & 23.4 \\
\hline \multirow{2}{*}{ Academic level } & \multicolumn{2}{|c|}{ Bachelor (continuous) } & 67 & 47.5 \\
\hline & \multicolumn{2}{|c|}{ Bachelor (discontinuous) } & 74 & 52.5 \\
\hline \multirow{2}{*}{ Academic degree } & \multicolumn{2}{|c|}{ Environmental health } & 103 & 73.0 \\
\hline & \multicolumn{2}{|c|}{ Occupational health } & 38 & 27.0 \\
\hline \multirow{2}{*}{ Marital status } & \multicolumn{2}{|c|}{ Single } & 35 & 25.4 \\
\hline & \multicolumn{2}{|c|}{ Married } & 106 & 74.6 \\
\hline \multirow{3}{*}{ Age } & \multicolumn{2}{|c|}{$20-22$} & 43 & 30.5 \\
\hline & \multicolumn{2}{|c|}{ 23-25 } & 83 & 58.9 \\
\hline & \multicolumn{2}{|c|}{26 and older } & 15 & 10.6 \\
\hline \multirow{5}{*}{$\begin{array}{l}\text { Filed of education } \\
\text { Educational level }\end{array}$} & \multirow{3}{*}{ Continuous } & Second & 12 & 17.9 \\
\hline & & Fourth & 29 & 43.3 \\
\hline & & Sixth & 26 & 38.8 \\
\hline & \multirow{2}{*}{ Discontinuous } & First & 41 & 55.4 \\
\hline & & Third & 33 & 44.6 \\
\hline
\end{tabular}


The objective was assessing the prevalence of anxiety among this group of students. The participants' age ranged from 22 to 39 years with a mean score of 25.8. In total, 33 male and 108 female students completed the questionnaire. Other demographic features of the participants are displayed in table 1 .
The prevalence of state anxiety (almost severe, severe, very severe) among the studied participants was $29.1 \%(n=41)$, whereas that of trait anxiety (almost severe, severe, very severe) was $20.6 \%(\mathrm{n}=21)$. Table 2 illustrates various levels of state and trait anxiety among the participating students.

Table 2: Distribution of state and trait anxiety among participating students $(n=141)$

\begin{tabular}{ccccc}
\hline \multirow{2}{*}{ Level of stress } & \multicolumn{2}{c}{ State anxiety } & \multicolumn{2}{c}{ Trait anxiety } \\
\cline { 2 - 5 } & Frequency & Percentage (\%) & Frequency & Percentage (\%) \\
\hline Mild & 11 & 7.80 & 0 & 0 \\
\hline Below moderate & 37 & 26.2 & 5 & 3.50 \\
\hline Above moderate & 52 & 36.9 & 107 & 75.9 \\
\hline Almost severe & 31 & 22.0 & 29 & 20.6 \\
\hline Severe & 9 & 6.40 & 0 & 0 \\
\hline Very severe & 1 & 0.70 & 0 & 100 \\
\hline Total & 141 & 100 & 141 & 0 \\
\hline
\end{tabular}

With respect to state anxiety, $30.1 \%$ of university students of environmental health had moderate or below moderate anxiety, while $29.1 \%$ of them suffered from above moderate state anxiety. Considering students of occupational health, the prevalence of below moderate state anxiety was $15.8 \%$ and the prevalence of above moderate state anxiety was $57.9 \%$. The highest prevalence of trait anxiety for students of environmental and occupational health belonged to below moderate anxiety with rates of $72.8 \%$ and $84.2 \%$, respectively. Table 3 displays various levels of state and trait anxiety for each of the majors.

Table 3: The prevalence of state and trait anxiety among environmental and occupational health students $(\mathrm{n}=$ 141)

\begin{tabular}{ccccc}
\hline \multirow{2}{*}{ Level of stress } & \multicolumn{4}{c}{ Filed of education } \\
\cline { 2 - 5 } & \multicolumn{2}{c}{ Environmental health } & \multicolumn{2}{c}{ Occupational health } \\
\cline { 2 - 5 } & State anxiety(\%) & Trait anxiety (\%) & State anxiety (\%) & Trait anxiety (\%) \\
\hline Mild & 8.70 & & 5.30 & - \\
\hline Below moderate & 30.1 & 4.90 & 15.8 & - \\
\hline Above moderate & 29.1 & 72.8 & 57.9 & 84.2 \\
\hline Almost severe & 23.3 & 22.3 & 18.4 & - \\
\hline Severe & 7.80 & - & 2.60 & - \\
\hline Very severe & 1 & - & - & 15.8 \\
\hline
\end{tabular}

The results of Kolmogorov-Smirnov test revealed that the collected data were normally distributed $(\mathrm{P}=0.879)$. The results of Pearson correlation indicated that there was a significant, negative relationship between age and anxiety $(\mathrm{r}=-0.245, \mathrm{P}=0.004)$ and GPA and anxiety $(\mathrm{r}=-0.18, \mathrm{P}=0.035)$. Therefore, older students and students with better scores experience lower levels of anxiety.

Furthermore, independent samples t-test and one-way ANOVA were carried out to find if different variables demonstrated in table 4 cause a significant difference in students' scores of state and trait anxiety. 
The results of tests also demonstrated that there was no statistically considerable difference between students of environmental and occupational health in terms of their state and trait anxiety. As indicated in table 4, students' gender, academic level, and academic period did not cause any significant difference in their state and trait anxiety. The results, which are illustrated in this table, showed that there was a significant negative relationship between anxiety scores and GPA and age. More specifically, students with lower scores and younger age suffered from higher levels of anxiety.

In addition, the results of one-way ANOVA showed that there was no significant difference between the state $(\mathrm{P}=0.690)$ and trait $(\mathrm{P}=0.090)$ anxiety scores of students who were studying in different semesters (ranging from the first to the eighth semester).

Table 4: Anxiety mean scores in the light of different studied variables

\begin{tabular}{|c|c|c|c|c|c|}
\hline \multirow{2}{*}{\multicolumn{2}{|c|}{ Variable }} & \multicolumn{2}{|c|}{ State anxiety } & \multicolumn{2}{|c|}{ Trait anxiety } \\
\hline & & Mean \pm SD & $\mathbf{P}$ & Mean \pm SD & $\overline{\mathbf{P}}$ \\
\hline \multirow{2}{*}{ Gender } & Female & $47.07 \pm 10.43$ & \multirow{2}{*}{0.550} & $49.98 \pm 4.27$ & \multirow{2}{*}{0.870} \\
\hline & Male & $45.81 \pm 10.82$ & & $49.31 \pm 3.38$ & \\
\hline \multirow{2}{*}{ Marital status } & Single & $48.09 \pm 4.20$ & \multirow{2}{*}{0.410} & $49.9 \pm 2.7$ & \multirow{2}{*}{0.320} \\
\hline & Married & $46.4 \pm 2.0$ & & $48.3 \pm 3.2$ & \\
\hline \multirow{3}{*}{ Age } & 20-22 years & $47.8 \pm 11.03$ & \multirow{3}{*}{0.039} & $50.16 \pm 5.84$ & \multirow{3}{*}{0.040} \\
\hline & 23-25 years & $46.6 \pm 9.8$ & & $49.4 \pm 4.4$ & \\
\hline & Over 26 years & $44.5 \pm 47.4$ & & $49.2 \pm 3.5$ & \\
\hline \multirow{2}{*}{ Academic level } & Continuous & $46.27 \pm 10.65$ & \multirow{2}{*}{0.580} & $49.16 \pm 4.40$ & \multirow{2}{*}{0.480} \\
\hline & Discontinuous & $47.24 \pm 10.41$ & & $49.64 \pm 3.70$ & \\
\hline \multirow[t]{2}{*}{ Academic year } & $\begin{array}{c}\text { Students of the first, } \\
\text { second, and third } \\
\text { years }\end{array}$ & $46.6 \pm 10.5$ & \multirow[t]{2}{*}{0.440} & $49.4 \pm 4.04$ & \multirow[t]{2}{*}{0.800} \\
\hline & Interns & $50.0 \pm 8.9$ & & $49.8 \pm 5.1$ & \\
\hline \multirow{3}{*}{ GPA status } & Lower than 14 & $57.0 \pm 6.3$ & \multirow{3}{*}{0.034} & $54.0 \pm 4.4$ & \multirow{3}{*}{0.005} \\
\hline & Between 14 and 16 & $46.75 \pm 11.08$ & & $49.4 \pm 3.8$ & \\
\hline & Above 16 & $46.37 \pm 10.30$ & & $48.8 \pm 3.8$ & \\
\hline \multirow{2}{*}{ Field of study } & Environmental health & $46.56 \pm 11.09$ & \multirow{2}{*}{0.650} & $49.24 \pm 4.38$ & \multirow{2}{*}{0.320} \\
\hline & Occupational health & $47.36 \pm 8.81$ & & $49.89 \pm 3.10$ & \\
\hline
\end{tabular}

SD: Standard deviation; GPA: Grade point average

\section{Discussion}

This study, which was conducted among 141 environmental and occupational health students investigated the prevalence of anxiety among these participants in order to devise a better plan to reduce this negative psychological state. The participating students suffered from different levels of state and trait anxiety. With respect to state anxiety, $7.8 \%$ of them had mild, $63.1 \%$ had moderate, and $29.1 \%$ had severe anxiety. Regarding trait anxiety, $79.4 \%$ of students suffered from moderate anxiety, while $20.6 \%$ had severe anxiety. State anxiety is situational and stems from stressful conditions (e.g. arguments, loss of social opportunities, security threats, and loss of health) and may appear in a particular period of a person's life (11). In contrast, trait anxiety has to do with individual differences in responding to threatening situations with various levels of state anxiety (12).

Although an increasing number of students are studying environmental and occupational health, few studies have focused on the prevalence of anxiety among them. The overwhelming majority of research projects have concentrated on the prevalence of anxiety among students of medicine. Some of the findings of these studies are in contrast with the ones obtained in the current research. For example, a study focusing on anxiety among 196 female university students of Tehran 
University of Medical Sciences, Tehran, Iran, reported an overall prevalence rate of $28.5 \%$, a prevalence of $25.5 \%$ for state anxiety, and a prevalence of $16.3 \%$ for trait anxiety. Various studies that have investigated the anxiety among students of medicine in different countries since 2006 have indicated a prevalence rate of $20.3 \%$ to $43 \%$ (17-22). It should be noted that, methodologically speaking, it is not appropriate to compare the results of this study with those of research projects focusing on students of medicine because the students of this field have disparate economic, educational, and social problems compared to students of healthrelated majors.

Anxiety can be considered as one of the main neuropsychiatric disorders and one of the main reasons for depression. If anxiety lasts for a long time, it leads to depression. Anxiety is an unpleasant feeling of stress that stems from an unknown origin. Some psychologists believe that all psychological diseases are the result of anxiety (23). The results of a study, which was carried out in Iran University of Medical Sciences, Tehran, Iran, showed that $50.5 \%$ of university students suffer from various degrees of depression, while $73 \%$ of them were diagnosed with different levels of anxiety. This study also indicated that there is a significant positive correlation between university students' anxiety and depression scores. More precisely, students who suffer from greater anxiety are also more likely to experience severer forms of depression. Other studies have also displayed that anxiety and depression are prevalent among university students and there is a considerable direct association between these two constructs (24). In fact, students experience various forms of stress during their studies. The presence of stressors and lack of ability to control them can cause anxiety, depression, and other psychological problems among university students. A study investigated depression among university students of Sabzevar School of Public Health, Razavi Khorasan, Iran, and demonstrated that in total, $41.05 \%$ of students suffered from various forms of depression (25). Also, the prevalence of depression among students of occupational health was $9.4 \%$.

This study indicated that sever forms of state anxiety were more prevalent than those of trait anxiety, a finding that is supported by previous studies $(26,27)$. It also demonstrated that interns were more prone to anxiety compared to their counterparts who were still studying theoretical courses (during the first three years of university). This difference, however, was not statistically significant. Greater prevalence of anxiety among interns may be attributed to the fact that they enter a new environment and have to deal with its particular challenges and problems. Moreover, this greater prevalence may be due to the type of courses that are presented during the internship, lack of close relationship between the courses and the reality of the working milieu, and students' negative attitude toward an uncertain future because of lack of job security. Intern students may also suffer from greater anxiety because they are in the last year of their undergraduate studies and many of them are preparing themselves for the postgraduate university entrance exam. However, caution must be exercised in overgeneralizing the results of this study in this regard. More specifically, a limited number of interns participated in the current study. Thus, in order to be able to make more robust claims, larger sample sizes of interns should be included in future studies. According to the findings of this study, the mean score of anxiety was slightly greater among students of occupational health compared to their counterparts who were studying environmental health. Nonetheless, the results of statistical analysis failed to show any significant difference between the two groups. With regard to state anxiety, 29.1\% of students of environmental health and $57.9 \%$ of students of occupational health reported above moderate levels of anxiety. The highest prevalence among students of both majors belonged to below moderate level of anxiety with prevalence rates of $72.8 \%$ and $84.2 \%$ for 
students of environmental and occupational health, respectively.

Despite slightly greater prevalence of anxiety among single students (compared to their married counterparts), the results of statistical analysis showed no significant difference between the two groups. Some studies have demonstrated that single students are more likely to suffer from anxiety. On the contrary, some other studies have failed to show any significant difference between single and married students in terms of their level of anxiety $(17,24,25,28)$. Moreover, the results of this study showed that female students' mean score of anxiety was higher than that of their male counterparts. However, the results of data analysis demonstrated no significant difference between the two groups. This finding is in line with the results of some other studies $(24,29,30)$.

\section{Conclusion}

The participating students mainly suffered from moderate to high levels of anxiety. Policy makers should therefore devise appropriate plans to identify and eliminate students' problems in order to improve their mental health. It should be noted that university students play a substantial role in the future of society, hence utmost attempt must be made to address their psychological problems. In recent years, a larger number of students are admitted to the fields of medical sciences, including environmental and occupational health. It is therefore essential to identify the problems of such students in a timely manner and direct students who have problems to psychiatric counseling centers for special treatment. By so doing, many negative consequences will be prevented and students' mental health will eventually improve. Obviously, detecting the origins of anxiety in each field of study and planning to eliminate or minimize the effect of these sources can play a significant role in preventing anxiety and its consequences. Perhaps, a committee consisting of counselors, university professors, educational policy makers, and university students can be helpful in identifying and addressing the sources of anxiety. One limitation of this study was low number of community members (students) that should be addressed in future studies.

\section{Acknowledgment}

The authors of this paper would like to express their appreciation to the Research Deputy of Qazvin University of Medical Sciences who supported the researchers to conduct this study.

Conflict of interests: None declared.

\section{Reference}

1. Sprengel AD, Job L. Reducing student anxiety by using clinical peer mentoring with beginning nursing students. Nurse Educ 2004; 29(6):246-50.

2. Mohr WK. Psychiatric-mental health nursing: evidence-based concepts, skills, and practices. $7^{\text {th }}$ ed. Philadelphia, United States: Wolters Kluwer Health/Lippincott Williams \& Wilkins; 2009.

3. Johnson AJ, Marcus J, Hickman K, Barton D, Elkins G. Anxiety reduction among breast-cancer survivors receiving hypnotic relaxation therapy for hot flashes. Int J Clin Exp Hypn 2016; 64(4):37790.

4. Kunie K, Kawakami N, Shimazu A, Yonekura Y, Miyamoto Y. The relationship between work engagement and psychological distress of hospital nurses and the perceived communication behaviors of their nurse managers: A cross-sectional survey. Int J Nurs Stud 2017; 71:115-24.

5. Sreeramareddy CT, Shankar PR, Binu VS, Mukhopadhyay C, Ray B, Menezes RG. Psychological morbidity, sources of stress and coping strategies among undergraduate medical students of Nepal. BMC Med Educ 2007; 7(1):26.

6. Yildirım N, Karaca A, Cangur S, Ac1kgoz F, Akkus D. The relationship between educational stress, stress coping, self-esteem, social support, and health status among nursing students in Turkey: A structural equation modeling approach. Nurse Educ Today 2017; 48:33-9.

7. Rezaei Adaryani M, Azadi A, Ahmadi F, Vahedian Azimi A. Comparison of depression, anxiety, stress and quality of life in dormitories students of Tarbiat Modares University. Iranian Journal of Nursing Research 2007; 2(4-5):31-8.

8. Heravi M, Milani M. Investigating the effect ofrelaxation therapy on level of exam anxiety in 
nursing student at Shahed University of Medical Science [Internet]. 2003 [cited 2008 Nov]. Avaiable from: www.irandoc.org

9. Eberhart NK. Interpersonal predictors of stress generation and depressed mood [PhD thesis]. Los Angeles, United States: University of California; 2008.

10. Jamali HA, Ghalenoei M. Attitudes of environmental health and occupational health students toward their discipline and future career in Qazvin University of Medical Sciences in 2012. Iranian Journal of Medical Education 2013; 13(7):541-50.

11. Ghobari Banab B. The relationship between forgiveness and degrees of anxiety among the parents of execeptional and ordinary children. Methodology of Sicial Science and humanities 2002; 8(31):78-96.

12. Behdani F, Sargolzaei M, Ghorbani E. Study of the relationship between lifestyle and prevalence of depression and anxiety in the students of Sabzevar Universities. Journal of Sabzevar University of Medical Sciences 2000; 7(2):27-37.

13. Hutchinson M, Higson M, Cleary M, Jackson D. Nursing expertise: a course of ambiguity and evolution in a concept. Nurs Inq 2016; 23(4):290304.

14. Mousa OY, Dhamoon MS, Lander S, Dhamoon AS. The MD blues: under-recognized depression and anxiety in medical trainees. PLoS One 2016; 11(6): 0156554.

15. Gholami Booreng F, Mahram B, Kareshki H. Construction and validation of a scale of research anxiety for students. Iranian Journal of Psychiatry \& Clinical Psychology 2017; 23(1):78-93.

16. Panahi Shahri M. Preliminary evaluation of validity \& reliability of spielberger state-trait anxiety inventory [MA thesis]. Tehran: Tarbiat Modarres University; 1993.

17. Labbafinejad Y, Bossaghzade A. Assessment of anxiety prevalence and its contributing factors in female medical students of Tehran University of Medical Sciences in 2010-2011. Iran Occupational Health 2012; 9(3):32-8.

18. Tyssen R, Vaglum P, Grønvold NT, Ekeberg Ø. The relative importance of individual and organizational factors for the prevention of job stress during internship: a nationwide and prospective study. Med Teach 2005; 27(8):726-31.

19. Levine RE, Litwins SD, Frye AW. An evaluation of depressed mood in two classes of medical students. Acad Psychiatry 2006; 30(3):235-7.
20. Eller T, Aluoja A, Vasar V, Veldi M. Symptoms of anxiety and depression in Estonian medical students with sleep problems. Depress Anxiety 2006; 23(4):250-6.

21. Bunevicius A, Katkute A, Bunevicius R. Symptoms of anxiety and depression in medical students and in humanities students: relationship with big-five personality dimensions and vulnerability to stress. Int J Soc Psychiatry 2008; 54(6):494-501.

22. Wahed WYA, Hassan SKh. Prevalence and associated factors of stress, anxiety and depression among medical Fayoum University students. Alexandria Journal of Medicine 2017; 53(1):77-84.

23. Schumacher KL, Meleis AI. Transitions: a central concept in nursing. Image J Nurs Sch 1994; 26(2):119-27.

24. Dehdari T, Yarahmadi R , Taghdisi MH, Daneshvar R, Ahmad Poor J. The relationship between meaning in life and depression, anxiety and stress status among college students of Iran University of Medical Sciences in 2013. Journal of Health Education and Health Promotion 2013; 1(3):83-92.

25. Ershadi Kia B, Shajari A, Tayebi F, Yaghoobi Far MA. Identifying the prevalence and contributing factors of depression in students of health and health-related schools of Sabzevar University of Medical Sciences in academic year 2009-2010. Journal of Student Research Committee, Sabzevar University of Medical Sciences (Beyhagh) 2011; 16(1):33-43.

26. Mousavi R. Evaluation of the relationship of anxiety with economic, cultural \& social determinants in interns of Iran University of Medical Sciences in summer 2000. [MD thesis]. Tehran: Iran University of Medical Sciences; 2000.

27. Kh Fathizadeh. Evaluation of the frequency of anxiety in students of Imam Ali \& Imam Hasan dormitory of Iran University of Medical Sciences in 2003 [MD thesis]. Tehran: Iran University of Medical Sciences; 2003.

28. Jadoon NA, Yaqoob R, Raza A, Shehzad MA, Zeshan SC. Anxiety and depression among medical students: a cross-sectional study. J Pak Med Assoc 2010; 60(8):699-702.

29. Inam SN, Saqib A, Alam E. Prevalence of anxiety and depression among medical students of private university. J Pak Med Assoc 2003; 53(2):44-7.

30. Darabi M, Ashraf Aivazi AA, Gholami-Parizad E, Ghazanfari Z, Imanzad M. Test anxiety among Ilam UMS'students, 2012. Advances in Nursing \& Midwifery 2013; 23(82):1-7. 